\title{
CD34- human placenta-derived mesenchymal stem cells protect against heat stroke mortality in rats
}

\author{
Willie Lin ${ }^{1}$, Yogi Chang-Yo Hsuan ${ }^{1}$, Yu-Chin Su${ }^{1}$, Cheng-Hsien Lin ${ }^{1}$, Mao-Tsun Lin ${ }^{2}$, \\ Zi-Hao Chen ${ }^{3,4}$, Ching-Ping Chang ${ }^{2,4,5}$ and Kao-Chang Lin ${ }^{4,6}$ \\ ${ }^{1}$ Meridigen Biotech Co., Ltd., Taipei, Taiwan \\ ${ }^{2}$ Department of Medical Research, Chi Mei Medical Center, Tainan, Taiwan \\ ${ }^{3}$ Institute of Molecular Medicine, College of Medicine, National Cheng Kung University, Tainan, Taiwan \\ ${ }^{4}$ Department of Biotechnology, Southern Taiwan University of Science and Technology, Tainan, Taiwan \\ ${ }^{5}$ The Ph.D. Program for Neural Regenerative Medicine, Taipei Medical University, Taipei, Taiwan \\ ${ }^{6}$ Department of Neurology, Chi Mei Medical Center, Tainan, Taiwan \\ Correspondence to: Ching-Ping Chang, email: jessica.cpchang@gmail.com, jessica@stust.edu.tw \\ Kao-Chang Lin, email: gaujang@mail2000.com.tw
}

Keywords: heat stroke; placenta; mesenchymal stem cells; ischemia; inflammation

Received: August 24, $2017 \quad$ Accepted: December 09, $2017 \quad$ Published: December 15, 2017

Copyright: Lin et al. This is an open-access article distributed under the terms of the Creative Commons Attribution License 3.0 (CC BY 3.0), which permits unrestricted use, distribution, and reproduction in any medium, provided the original author and source are credited.

\section{ABSTRACT}

CD34 is a transmembrane phosphoglycoprotein used to selectively enrich bone marrow in hematopoietic stem cells for transplantation. Treating rats with $\mathrm{CD} 4^{+}$cells derived from human umbilical cord blood before or after heat stroke has been shown to promote survival. We investigated whether CD34- human placenta-derived stem cells (PDMSCs) could improve survival following heat stroke in rats. Rats were subjected to heat stress $\left(42^{\circ} \mathrm{C}\right.$ for $\left.98 \mathrm{~min}\right)$ to induce heat stroke. Intravenous administration of PDMSCs 1 day before or immediately after the onset of heat stroke improved survival by $60 \%$ and $20 \%$, respectively. Pre-treatment with CD34- PDMSCs protected against heat stroke injury more effectively than that treatment after injury. PDMSCs treatment attenuated cerebrovascular dysfunction, the inflammatory response, and lipid peroxidation. These data suggest human PDMSCs protect against heat stroke injury in rats. Moreover, these effects do not require the presence of $\mathrm{CD}_{34}{ }^{+}$cells.

\section{INTRODUCTION}

Cardiovascular disease is the primary cause of death in the United States [1]. An inverse correlation between cardiovascular disease and the number and function of circulating angiogenic cells (CACs) was reported previously [2]. CACs are endothelial progenitor cells, which are categorized based on the expression of cell surface markers such as CD34. CD34+ cells have been evaluated for the treatment of ischemic conditions [3, 4]. Systemic administration of $\mathrm{CD}^{+} 4^{+}$cells derived from human umbilical cord blood (HUCB) was shown to reduce heat stroke-induced mortality in rats $[5,6]$.
$\mathrm{CD}^{-} 4^{-}$cells have also been investigated for the treatment of several cardiovascular diseases. For example, mononuclear cell (MNC) fractions isolated from HUCB that were depleted of $\mathrm{CD} 34^{+}$stem cells reduced ischemic brain injury in a rat model of stroke $[7,8]$. Additionally, $\mathrm{CD} 45^{+} / \mathrm{CD} 4^{-} / \mathrm{Lin}^{-}$stromal cells derived from bone marrow protected against ischemia and reperfusion injuries in rats [9]. Finally, circulating CD $31^{+} / \mathrm{CD} 34^{-}$ angiogenic cells improved hind limb ischemic injuries in mice [10].

The human placenta is a source of mesenchymal stem cells that have the ability to differentiate into cardiomyocytes, smooth muscle cells, osteoblasts, 
adipocytes, endodermic pancreatic islet cells, liver cells, ectodermic neurons, and astrocytes [11-13]. Flow cytometry analysis has indicated that human placentaderived mesenchymal stem cells (PDMSCs) are CD34[14-16]. PDMSCs have been shown to promote healing in animal models of myocardial infarction, Parkinson's disease, diabetes mellitus, and spinal cord injury [14, 17-20].

In this study, we investigated whether CD34 PDMSCs could improve survival in a rat model of heat stroke by altering the cerebrovascular, inflammatory, and lipid peroxidation responses.

\section{RESULTS}

\section{PDMSCs treatment improves survival in a rat model of acute heat stroke}

The experimental design is illustrated in Figure 1. Following heat stress at $42^{\circ} \mathrm{C}$ for $98 \mathrm{~min}$, rats were maintained at room temperature $\left(26^{\circ} \mathrm{C}\right)$ and survival monitored over $300 \mathrm{~min}$. Survival was lower among rats treated with vehicle solution 1 day before heat stress $(\mathrm{V}+\mathrm{HS})$ compared to normothermic control rats treated with vehicle solution 1 day before room temperature exposure ( $0 \%$ vs. $100 \%$, respectively) (Figure 2). In contrast, survival was higher among heat stroke rats treated with PDMSCs 1 day before heat stress (PDMSCs+HS), and rats treated with PDMSCs immediately after heat stress (PDMSCs[post]+HS) compared to the $\mathrm{V}+\mathrm{HS}$ group
(60\% and 20\%, respectively, compared to 0\%) (Figure 2). The protective effects of pre-treatment with PDMSCs were superior to those of post-treatment (Figure 2).

\section{PDMSCs treatment reduces hyperthermia, hypotension, and cerebral ischemia after heat stress}

The V+HS group had higher body core temperatures 30 min following heat stress compared to the $\mathrm{V}+\mathrm{NC}$ or $\mathrm{PDMSCs}+\mathrm{NC}$ groups $\left(41-41.5^{\circ} \mathrm{C}\right.$ vs. $36-37^{\circ} \mathrm{C}$, respectively) (Figure $3 \mathrm{~A}$ and $3 \mathrm{~B}$ ). The $\mathrm{V}+\mathrm{HS}$ group also had higher levels of several indicators of cerebral ischemia compared to the $\mathrm{V}+\mathrm{NC}$ group (glutamate: $26 \pm 15 \mu \mathrm{mol} / \mathrm{L}$ vs. $5 \pm 1 \mu \mathrm{mole} / \mathrm{L}$ and lactate/pyruvate: $0.18 \pm 0.04 \mu \mathrm{mol} / \mathrm{L}$ vs. $0.03 \pm 0.02 \mu \mathrm{mol} / \mathrm{L}$, respectively) (Figure $3 \mathrm{G}$ and $3 \mathrm{H}$ ). In contrast, the $\mathrm{V}+\mathrm{HS}$ group had a lower mean arterial pressure (MAP) $(20 \pm 5 \mathrm{mmHg}$ vs. 78 $\pm 3 \mathrm{mmHg}$, respectively), heart rate (HR; 120 beats/min vs. 468 \pm 52 beats/min, respectively), and cerebral blood flow (CBF; $200 \pm 24$ BPU vs. $400 \pm 39$ BPU, respectively) compared to the $\mathrm{V}+\mathrm{NC}$ group (Figure $3 \mathrm{C}, 3 \mathrm{D}$ and $3 \mathrm{E}$ ). PDSMC treatment reduced hyperthermia (Figure $3 \mathrm{~B}$ and $3 \mathrm{~F}$ ), cerebral ischemia, hypotension, and bradycardia caused by heat stroke (Figure 3).

\section{PDMSCs treatment attenuates the inflammatory response and lipid peroxidation after heat stress}

The $\mathrm{V}+\mathrm{HS}$ group had higher serum tumor necrosis factor- $\alpha$ (TNF- $\alpha$, Figure 4A), interleukin-1 $\beta$ (IL-1 $\beta$,

\section{Experimental Design}

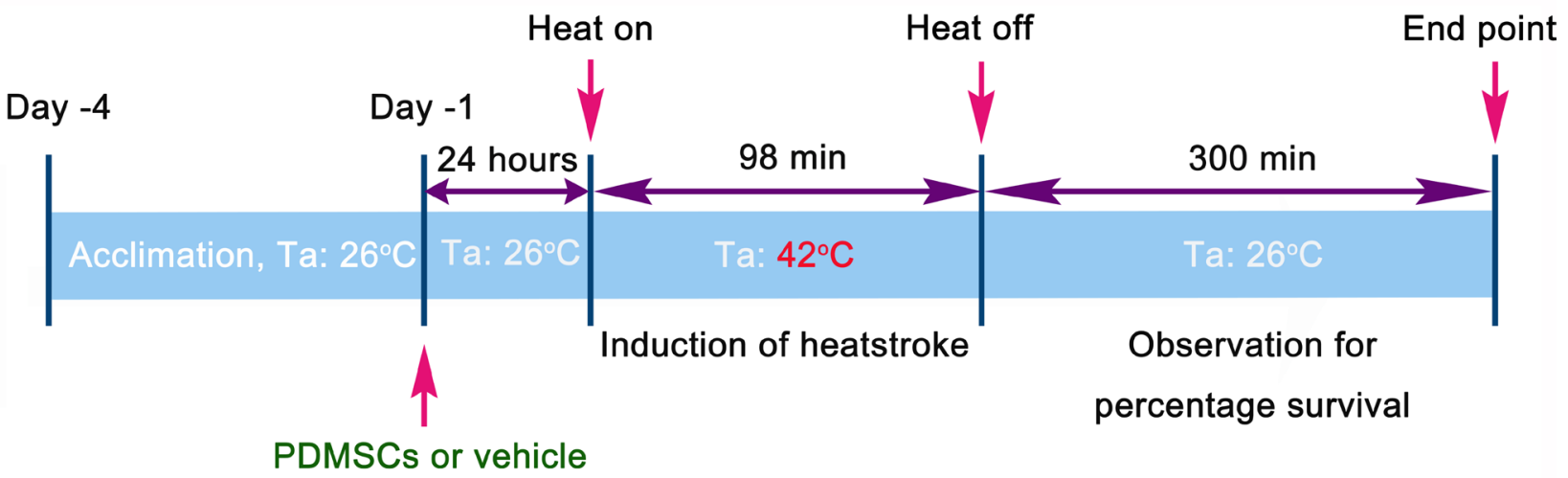

infusion via tail vein

\section{Experimental groups:}

1. Normothermic control group treated with vehicle solution one day before room temperature exposure $\left(26^{\circ} \mathrm{C}\right)(\mathrm{V}+\mathrm{NC})$

2. Normothermic control group treated with PDMSCs one day before room temperature exposure $\left(26^{\circ} \mathrm{C}\right)(\mathrm{PDMSCs}+\mathrm{NC})$

3. Heat stroke rats treated with vehicle solution one day before heat stress $\left(42^{\circ} \mathrm{C}\right)(\mathrm{V}+\mathrm{HS})$

4. Heat stroke rats treated with PDMSCs one day before heat stress $\left(42^{\circ} \mathrm{C}\right)$ (PDMSCs+HS)

5. Heat stroke rats treated with PDMSCs immediately after heat stress $\left(42^{\circ} \mathrm{C}\right)(\mathrm{PDMSCs}[\mathrm{post}]+\mathrm{HS})$

Figure 1: Experimental design and definitions of groups. 
Figure 4B), and malondialdehyde (MDA, Figure 4C) levels compared to the $\mathrm{V}+\mathrm{NC}$ group 30 min after heat stress $(193 \pm 25 \mathrm{pg} / \mathrm{mL}$ vs. $8 \pm 2 \mathrm{pg} / \mathrm{mL}, 427 \pm 43 \mathrm{pg} / \mathrm{mL}$ vs. $43 \pm 14 \mathrm{pg} / \mathrm{mL}$, and $843 \pm 67 \mathrm{nmol} / \mathrm{mL}$ vs. $518 \pm 40$ $\mathrm{nmol} / \mathrm{L}$, respectively) (Figure 4). Thus, PDMSCs treatment attenuates the inflammatory response and lipid peroxidation following heat stress.

\section{DISCUSSION}

Environmental heat stress causes subcutaneous vasodilation, increased metabolism, splanchnic vasocontraction, hypotension, intracranial hypertension, and cerebral ischemia in rodents [21]. We found that vehicle-treated rats displayed hyperthermia, hypotension, cerebral ischemia and oxidative stress, and activation of the inflammatory response following heat stroke resulting in mortality. Intravenous administration of PDMSCs 1 day before or immediately after the onset of heat stroke increased the percentage survival to $60 \%$ and $20 \%$, respectively, compared to $0 \%$ in controls. The protective effects of pre-treatment with PDMSCs were superior to those of post-treatment. PDMSCs therapy may attenuate heat stroke-induced mortality by attenuating hyperthermia, hypotension, cerebral ischemia and oxidative injury, and the inflammatory response.

Heat stroke contributes considerably to morbidity and mortality in a high environmental temperature [21]. About $30 \%$ of heat stroke survivors after whole body cooling, the current therapy of choice for heat stroke, experience disability and neurological dysfunction [22-24]. Many studies have demonstrated the beneficial effects of MSCs such as trophic factor-mediated neuroprotection, enhanced angiogenesis and neurogenesis, and modulate neuroinflammation [25]. In order to control the occurrence of the heat stroke, the prevention strategy

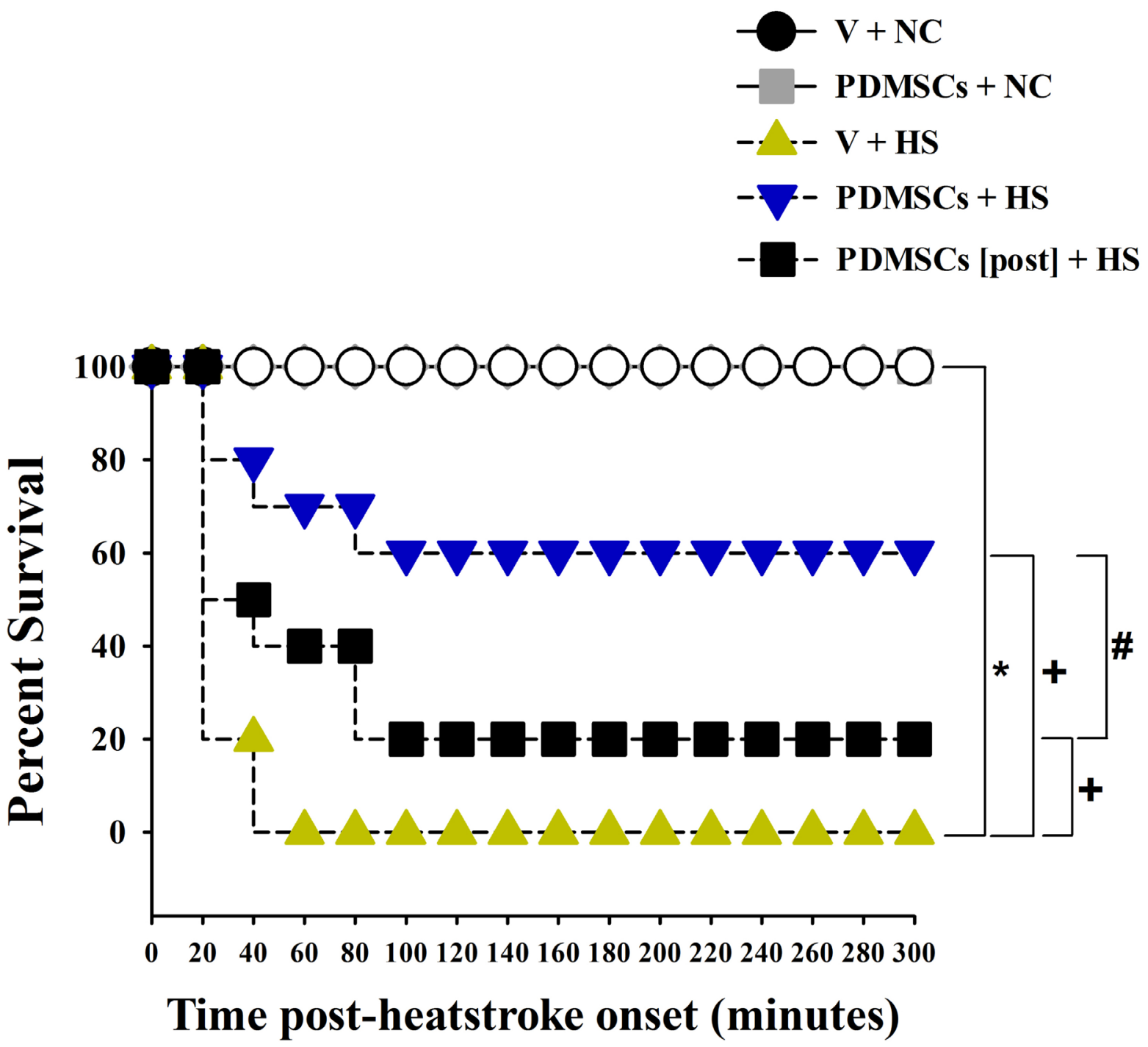

Figure 2: Kaplan-Meier analysis followed by log-rank tests were performed to determine percent survival in each group $(\boldsymbol{n}=\mathbf{1 0}) .{ }^{*} p<0.05$ vs. the NC group, ${ }^{+} p<0.01$ vs. the $\mathrm{V}+\mathrm{HS}$ group. ${ }^{*} p<0.05$ vs. the PDMSCs+HS group. 
is better than the post- heat stroke cure. Indeed our present data show that PDMSCs treatment immediately after heat stroke, the beneficial effect was inferior to those of pretreatment. Therefore, our results strongly recommend that a prophylactic dose of PDMSCs can be considered for those who intend to work or exercise in a hot environment.

A

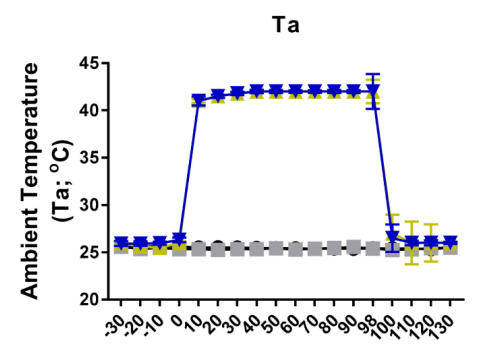

- $\mathrm{V}+\mathrm{NC}$

- PDMSCs+NC

- V+HS

$\neg$ PDMSCs+HS
Our data differ from those of previous findings supported by Chen and colleagues $[6,26]$. They found that systemic administration of $\mathrm{CD} 4^{+}$cells derived from HUCB also promoted survival in heat stroke rats by suppressing the inflammatory response. In contrast, our present data showed that systemic administration of $\mathrm{CD}^{3} 4^{-}$PDMSCs shared with the CD $34^{+}$HUCB the

E

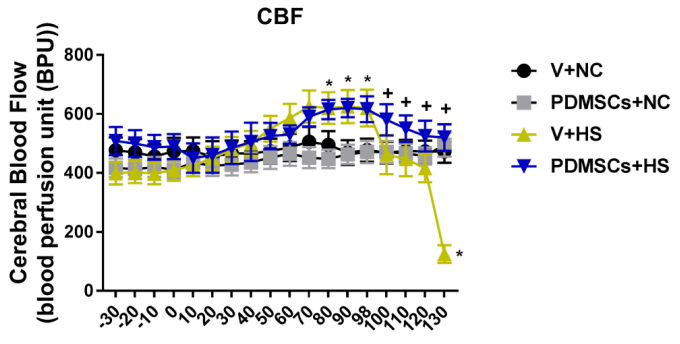

F

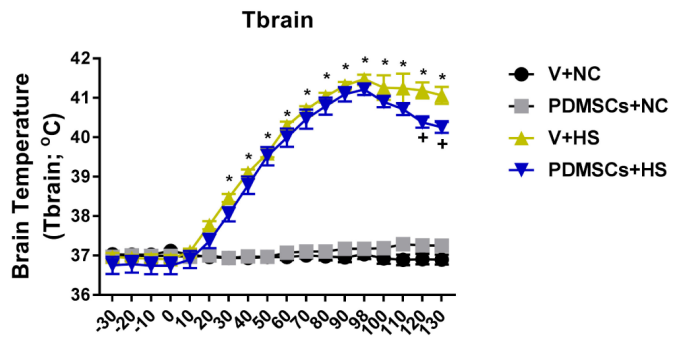

$\mathbf{G}$

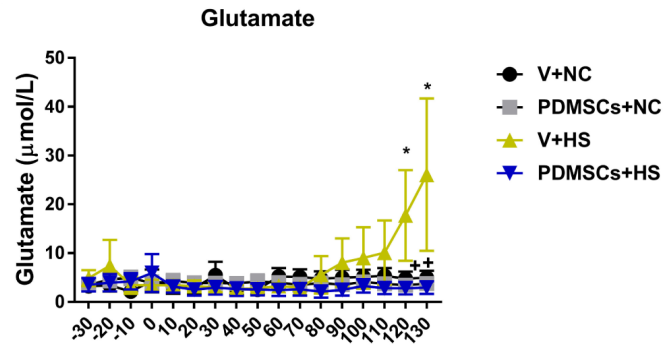

H

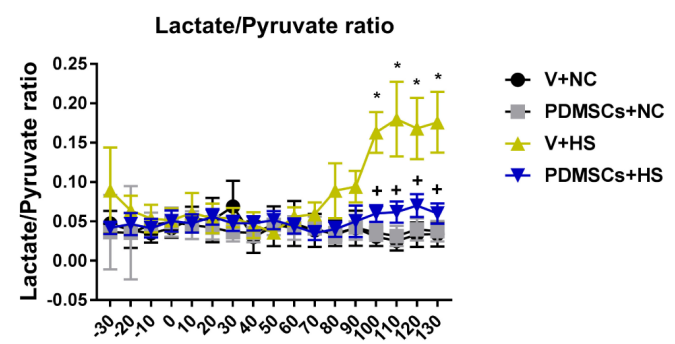

Figure 3: Functional recovery after PDMSCs treatment in a rat model of acute heat stroke. PDMSCs were administrated intravenously 1 day before heat stress and the physiological response analyzed in each group $(n=10)$. Physiological functions include: (A) ambient temperature, Ta; (B) colon temperature, Tco; (C) mean arterial blood pressure, MABP; (D) heart rate, HR; (E) cerebral blood flow, CBF; (F) brain temperature, Tbrain; $(\mathbf{G})$ brain levels of glutamate; and $(\mathbf{H})$ brain levels of lactate/pyruvate ratio. $p<0.05$ for the $\mathrm{V}+\mathrm{HS}$ vs. V+NC group; ${ }^{+} p<0.05$ for the PDMSCs $+\mathrm{HS}$ vs. $\mathrm{V}+\mathrm{HS}$ group. Data are presented as the mean $\pm \mathrm{S} . \mathrm{D}$. 
same protective effects. Both CD34- PDMSCs and $\mathrm{CD}^{+} 4^{+}$HUCB equally attenuated heat stroke-induced overexpression of both IL- $1 \beta$ and TNF- $\alpha$ in rats. These pro-inflammatory cytokines promote pyrogenesis, systemic inflammation, increased vascular permeability, and hypotension in response to heat stroke [27]. Putting together, PDMSCs may promote survival in heat stroke by a protective cell population without the presence of $\mathrm{CD} 34^{+}$ cells.

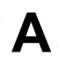

TNF- $\alpha$

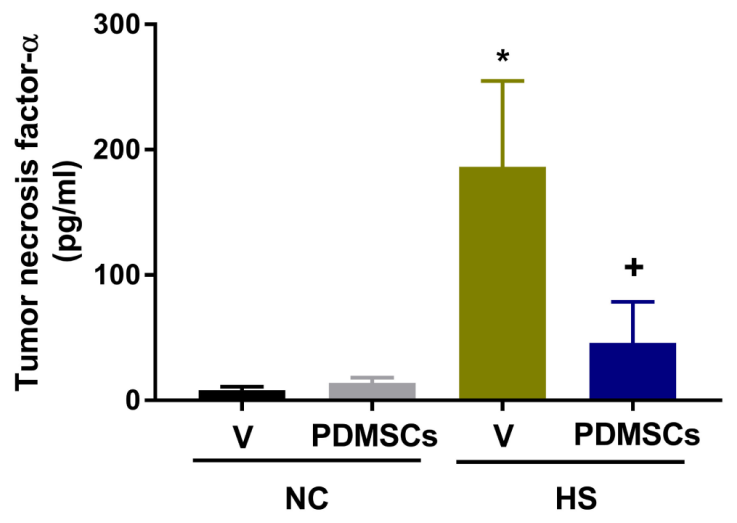

B

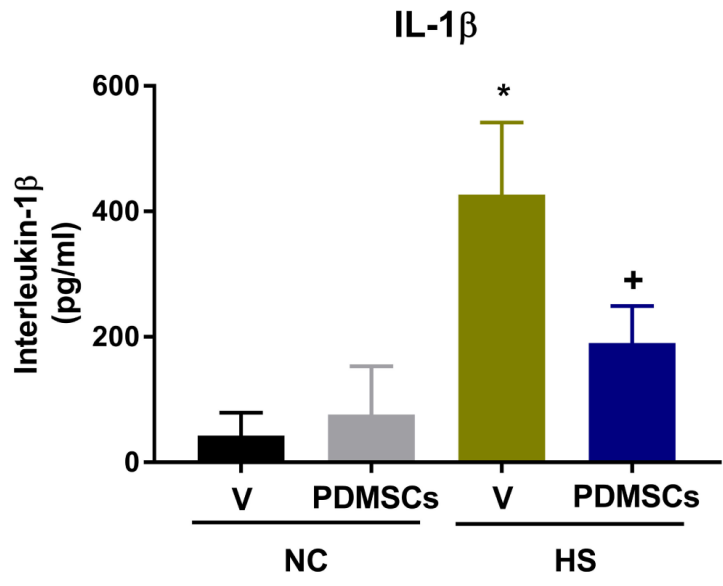

C

MDA

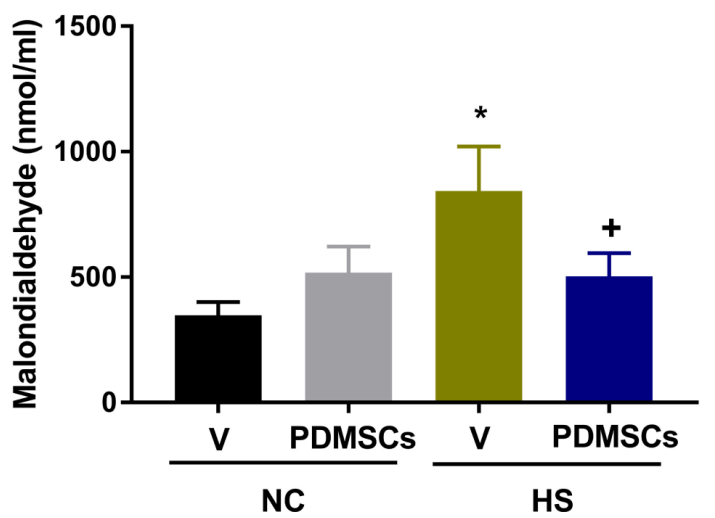

Figure 4: Analysis of the levels of (A) tumor necrosis factor-a (TNF-a), (B) interleukin-1b (IL-1b), and (C) malondialdehyde (MDA) following treatment with PDMSCs. PDMSCs were administered intravenously 1 day before heat stress, and the effects on serum TNF- $\alpha$, $\mathrm{IL}-1 \beta$, and MDA analyzed in each group $(n=10)$. Data are presented as the mean \pm S.D. ${ }^{*} p<0.05$ for the $\mathrm{V}+\mathrm{HS}$ vs. V+NC group; ${ }^{+} p<$ 0.05 for the PDMSCs+HS vs. V+HS group. 
Our findings are supported by data from other disease models. For example, intravenous administration of either HUBC-derived MNCs, MNC fractions enriched for $\mathrm{CD}_{3} 4^{+}$stem/progenitor cells, or $\mathrm{MNC}$ fractions depleted of $\mathrm{CD}^{+} 4^{+}$stem/progenitor cells reduced neurological injury and lesion volume in ischemic rats following stroke [28]. MNCs had the greatest effects compared to the other fractions. Intravenous administration of bone marrow-derived CD $45^{+} / \mathrm{CD}^{-} 4^{-} / \mathrm{lin}^{-}$ stroma cells protected against ischemia/reperfusion heart injury in rats [9]. Treatment with $\mathrm{CD} 34^{-} / \mathrm{CD} 31^{+} \mathrm{CACs}$ improved mouse hind limb ischemia to the same degree as CD34 cells [10]. Both HUCB MNCs and PDMSCs may protect against injuries caused by heat stroke through a protective cell population that has not yet been identified.

Rats that were not pretreated with PDMSCs prior to heat stress demonstrated a suppressed contractile function associated with stroke volume, ejection fraction, cardiac output, stroke work, and systolic pressure resulting in arterial hypotension. Similar results were described previously [29]. PDMSCs therapy could improve heat stroke-induced hypotension by increasing cardiac mechanical efficiency and decreasing arterial elastance.

We implanted a microdialysis probe into the hypothalamus of the rat brain to evaluate the impact of ischemia on the cells. If oxygen is available, pyruvate enters the citric acid cycle, which is the dominant producer of energy (ATP). Under ischemic conditions (inadequate blood supply), there is a decrease in the supply of oxygen and glucose. Therefore, there is an increase in cellular uptake of glucose in order to generate ATP through anaerobic glycolysis, which leads to a decrease in dialysate glucose concentration. This results in increased lactate production in order to generate $\mathrm{NAD}^{+}$for anaerobic glycolysis and an increase in the lactate-to-pyruvate ratio [30, 31]. Under ischemic conditions, glutamate is released from neurons and initiates a pathological influx of calcium leading to cell damage [32]. Calcium influx and glutamatergic excitotoxicity leads to structural alterations in the inner mitochondrial membrane. Disorganization of the electron transport chain increases radical oxygen species formation, which can lead to necrosis or apoptosis [32]. We found that increased cellular levels of ischemia (e.g., glutamate and lactate-to-pyruvate ratio) and lipid peroxidation markers (e.g., MDA) in response to heat stroke were attenuated by PDMSCs treatment.

The plasma levels of pro-inflammatory cytokines such as TNF- $\alpha$ and IL- $1 \beta$ are elevated following heat stroke [21, 33]. The increase in the levels of these cytokines may be correlated with heat stroke severity. We demonstrated that CD34- PDMSCs have antiinflammatory effects similar to those of HUCB-derived $\mathrm{CD} 4^{+}$cells in rats following heat stroke. Both cell populations could improve outcomes following heat stroke by preventing the overproduction of pro-inflammatory cytokines including IL- $1 \beta$ and TNF- $\alpha$.
Severe heat stress causes subcutaneous vasodilation and ischemia in multiple vital organs including both the heart and brain. Once recruited to the site of cardiac and/or cerebral ischemia, PDMSCs improve outcomes following heat stroke by stimulating tissue revascularization and neuroregeneration through differentiation into vascular or neuronal cells, the release of paracrine factors (e.g. growth factors, interleukins, neurotrophic factors), and through interactions between MSCs and the host tissue, which promotes vascular neogenesis and neuroregeneration [34, 35].

\section{MATERIALS AND METHODS}

\section{Animal experiments}

A total of 90 male Sprague-Dawley rats (10 weeks old, 248-329 g) were housed individually and allowed to access to food and water ad libitum. Animals were labeled with identifiers on the tail with a non-toxic, temporary pen. All procedures were performed under urethane anesthesia. Every effort was made to minimize the number of animals and limit pain and suffering.

\section{Induction of heat stroke}

All Sprague-Dawley rats were obtained from BioLASCO Taiwan Co., Ltd. (Taipei, Taiwan) to exclude the possibility of gender-related differences in heat tolerance. The rectal temperatures of the anesthetized rats were maintained at $36 \pm 1^{\circ} \mathrm{C}$ during the procedure using a water-circulating folded heating pad. The right femoral artery and vein were cannulated for measurement of the MAP and HR, and for cell delivery. Heat stroke was induced by increasing the temperature of the folded heating pad from $36^{\circ} \mathrm{C}$ to $42^{\circ} \mathrm{C}$ for approximately $98 \mathrm{~min}$ (Figure 1) [36]. Animals were then allowed to recover at room temperature $\left(26^{\circ} \mathrm{C}\right)$.

\section{PDMSCs isolation and culture}

Human PDMSCs were obtained from Meridigen Biotech Co., Ltd (Taipei, Taiwan). All donor women were 20-45 years old, negative for syphilis, HIV, CMV, HBsAg, and $\mathrm{HCV}$, and had no history of infectious diseases or complications during pregnancy. Donors provided written informed consent. Placental tissue was harvested under sterile conditions, rinsed with PBS, and cut into $1 \times 1 \times 1 \mathrm{~mm}^{3}$ pieces with scissors. Next, the specimens were digested with $100 \mathrm{~mL}$ of $2 \mathrm{mg} / \mathrm{mL}$ collagenase (NB6 GMP Grade, SERVA) in a $37^{\circ} \mathrm{C}$ incubator for 120 minutes. The digestion was terminated with the addition of culture media. Cell suspensions were centrifuged at $300 \mathrm{RCF}$ for 5 minutes. Supernatants were aspirated and the cells resuspended in $35 \mathrm{~mL}$ of complete media. Cell solutions were then seeded into T175 flasks (Nunc 
MaxiSorp; Thermo Fisher Scientific, Rockford, IL, USA). The cells were then cultured in a humidified incubator with $5 \% \mathrm{CO}_{2}$ at $37^{\circ} \mathrm{C}$. After 3 days, the culture media was replaced and non-adherent cells removed. The media was exchanged every 2-3 days. PDMSCs were passaged once they reached $80-90 \%$ confluence. For long-term storage, they were resuspended in CryoStor ${ }^{\circledR}$ CS10 and stored in a vapor phase liquid nitrogen tank.

\section{Identification of PDMSCs and analysis of differentiation capacity}

Flow cytometry analysis was performed using a BD FACSCanto II flow cytometer (Becton Dickinson Company, Franklin Lakes, NJ, USA). PDMSCs were $\mathrm{CD}_{4}{ }^{+}, \mathrm{CD}_{73}{ }^{+}, \mathrm{CD} 90^{+}$, and $\mathrm{CD} 105^{+}$, and $\mathrm{CD} 34^{-}, \mathrm{CD}^{-} 5^{-}$, $\mathrm{CD}_{11}^{-}$, and HLADR ${ }^{-}$(Figure 5). The cells were capable of differentiating into osteoblasts, adipocytes, and chondrocytes (Figure 6).

\section{PDMSCs preparation}

PDMSCs were removed from the liquid nitrogen tank and thawed in a $37^{\circ} \mathrm{C}$ water bath. Once thawed, the cells were mixed with culture media and plated at a density of 3,000 cells $/ \mathrm{cm}^{2}$ in a T175 flask. Once the cells reached $80 \%$ confluence, they were trypsinized for 2 minutes at $37^{\circ} \mathrm{C}$ and the trypsin neutralized with complete culture media. The cell suspension was centrifuged at 300 RCF for 5 minutes. The supernatant was aspirated and the cell pellet resuspended in normal saline. The final concentration was adjusted to $1 \times 10^{6}$ cells $/ \mathrm{mL}$.

\section{Experimental groups}

Animals were randomly divided into five groups: a (i) normothermic control (NC) group treated with vehicle solution (V) (1 mL/kg body weight) 1 day before room temperature exposure $(\mathrm{V}+\mathrm{NC})$; (ii) normothermic control group treated with PDMSCs $\left(1 \times 10^{6} / \mathrm{mL} / \mathrm{kg}\right.$ body weight) 1 day before room temperature exposure (PDMSCs+NC); (iii) heat stroke (HS) rats treated with

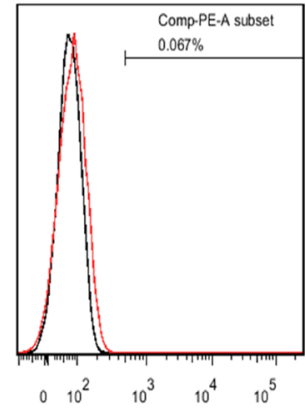

Negative Cocktail - PE

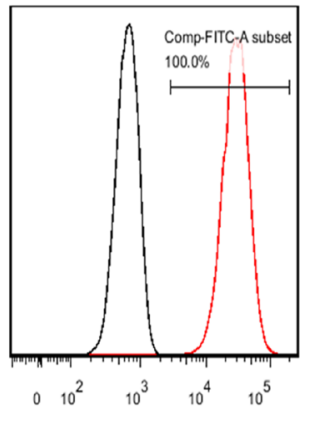

CD90 - FITC

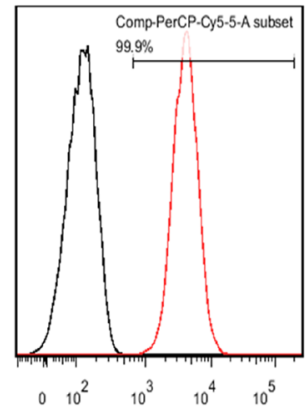

CD105 - PerCP-Cy5.5

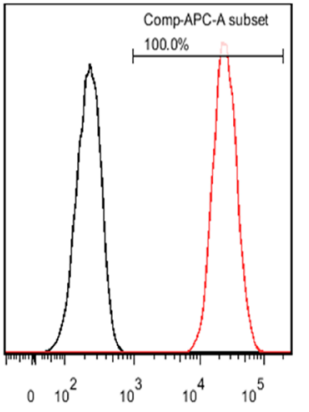

CD73 - APC

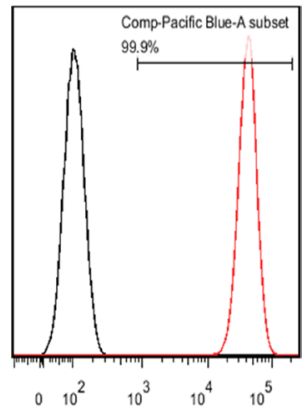

CD44 - Pacific Blue

Figure 5: The expression of PDMSC-specific CD cell surface markers was analyzed by flow cytometry. The BD stemflow ${ }^{\mathrm{TM}}$ human MSC Analysis kit was used to analyze MSC-specific cell surface markers (CD44, CD73, CD105, and CD90).

\section{Osteogenesis \\ Chondrogenesis}

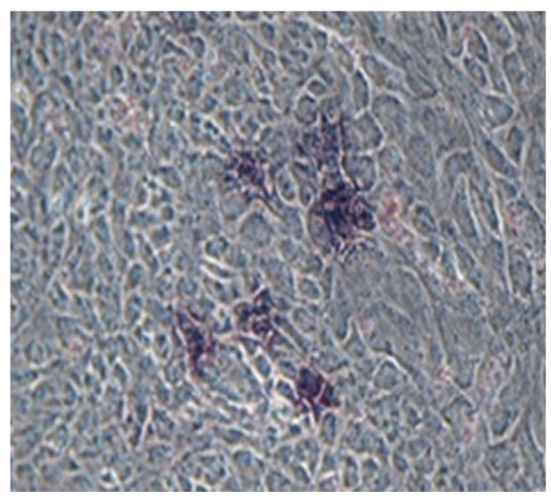

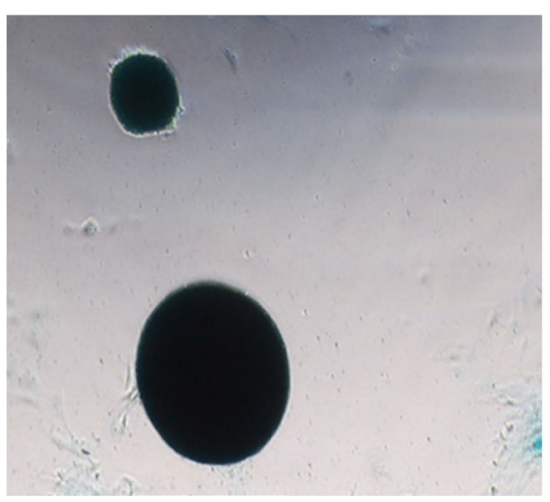

Adipogenesis

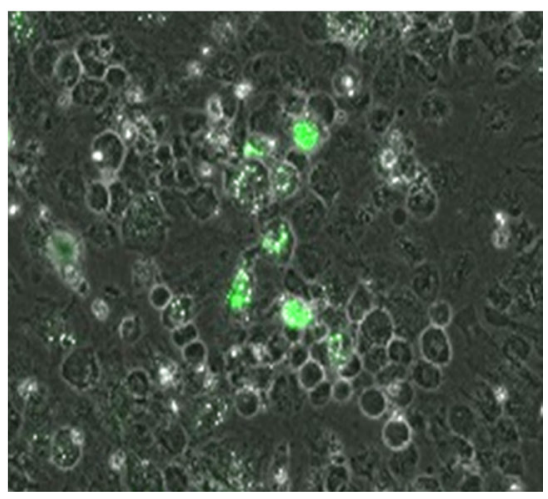

Figure 6: Tri-lineage differentiation analysis was performed to evaluate the differentiation capacity of human PDMSCs (from left to right: osteogenesis, chondrogenesis, and adipogenesis). Alkaline phosphatase (Sigma, B6404), Alcian blue (Sigma, A5268), and the AdipoRed Assay Reagent (Lonza, PT-7009) were used to stain osteocytes, chondrocytes, and adipocytes, respectively. 
vehicle solution (1 $\mathrm{mL} / \mathrm{kg}$ body weight) 1 day before heat stress (V+HS); (iv) HS rats treated with PDMSCs $\left(1 \times 10^{6} / \mathrm{mL} / \mathrm{kg}\right.$ body weight) 1 day before heat stress (PDMSCs+HS); and (v) HS rats treated with PDMSCs $\left(1 \times 10^{6} / \mathrm{mL} / \mathrm{kg}\right.$ body weight $)$ immediately after heat stress (PDMSCs[post]+HS). Each group consisted of 10 animals, which was the minimum to achieve statistical significance $(P<0.05)$.

\section{Measurement of the extent of hypothalamic ischemia}

Animals were positioned in a stereotaxic apparatus (Kopf 1406; Grass Instrument Co., Quincy, MA, USA) and probes inserted to measure local $\mathrm{CBF}$ and brain temperature. The probes consisted of a $100-\mu \mathrm{m}$ diameter thermocouple and two $230 \mu \mathrm{m}$ fibers. Measurements were acquired using OxyLite and OxyFlo instruments (Oxford optronix, Oxford, UK). The OxyLite 2000 is a two-channel device for measuring temperatures, whereas the OxyFlo 2000 is a two-channel laser Doppler perfusionmonitoring instrument for measuring $\mathrm{CBF}$. The probes were implanted into the hypothalamus using the atlas and coordinates of Paxinos and Watson [37].

In separate experiments, the skull was exposed after a midline excision and a burr hole was made in the skull for the insertion of a microdialysis probe $(4 \mathrm{~mm}$ in length, CMA/2: I.D. 150 mm, O.D. 220 mm; Carnegie Medicine, Stockholm, Sweden). The microdialysis probe was implanted stereotaxically into the hypothalamus. Microdialysates were collected every $10 \mathrm{~min}$ in a CMA/140 fraction collector (Carnegie Medicine, Stockholm, Sweden). Aliquots of the microdialysates $(5 \mu \mathrm{L})$ were injected into a CMA600 Microdialysis Analyzer (Carnegie Medicine) and markers of cellular ischemia including late/pyruvate and glutamate measured [38-40].

\section{Measurement of core body temperature and MAP in heat stroke rats}

Body core temperature was measured by inserting a thermocouple into the rectum of the animal. The MAP was measured by connecting the arterial cannulation (PE50 tube) to a transducer and a four-channel polygraph.

\section{Measurement of the serum levels of lipid peroxidation indicators and pro-inflammatory cytokines in heat stroke rats}

Blood samples were collected $30 \mathrm{~min}$ after termination of heat stress and centrifuged at 12,000 rpm. The supernatants were collected and stored at $-80^{\circ} \mathrm{C}$ until use in experiments. Lipid peroxidation was assessed by mixing serum with thiobarbituric acid to form a chromophore (absorbance at $532 \mathrm{~nm}$ ) and measuring MDA levels using the Esterbauer method [41]. The levels of pro-inflammatory cytokines including TNF- $\alpha$ and IL-1 $\beta$ in serum were measured using double antibody sandwich enzyme-linked immunosorbent assays according to the manufacturer's instructions (R\&D Systems, Minneapolis, MN, USA).

\section{Statistical analyses}

The data for multiple independent experiments are expressed as the mean \pm standard deviation (S.D.). Survival rates were compared using Kaplan-Meier analysis followed by log-rank tests. One-way analysis of variance followed Student-Newman-Keuls post-hoc tests was performed to analyze differences between multiple groups. A $P<0.05$ was considered significant.

\section{Ethics statement}

This study was approved by the Ethics Committee for Clinical Research at Chi Mei Medical Center (Tainan, Taiwan) (IRB serial no. 10405-008). All of the experimental protocols were approved by the Institutional Animal Care and Use Committee of Chi Mei Medical Center (Tainan, Taiwan) (ICAUC Approval No. 104042801). The study followed the Institutional and the National Ministry of Science and Technology guidelines for laboratory animal care.

\section{Abbreviations}

PDMSCs: human placenta-derived mesenchymal stem cells; HS: heat stroke; MAP: mean arterial pressure; $\mathrm{HR}$ : heart rate; $\mathrm{V}$ : vehicle; $\mathrm{NC}$ : normothermic control; CBF: cerebral blood flow; MDA: malondialdehyde; TNF- $\alpha$ : tumor necrosis factor alpha; IL-1 $\beta$ : interleukin-1 $\beta$; ICP: intracranial pressure; CPP: cerebral perfusion pressure.

\section{Author contributions}

WL, CPC, MTL, and KCL conceived of and designed the experiments. ZHC, CHL, and YCS performed the experiments. WL, YCYH, KCL, and CPC contributed reagents, materials and/or analytical tools. MTL, CPC, and KCL wrote the manuscript.

\section{CONFLICTS OF INTEREST}

The authors declare that there are no conflicts of interest. We wish to disclose that Drs. Willie Lin, Yogi Chang-Yo Hsuan, Cheng-Hsien Lin, and Yu-Chin Su are employees of Meridigen. 


\section{FUNDING}

This study was supported by grants from the Chi Mei Medical Center, Tainan, Taiwan (CMFHT 10504) and the Ministry of Science and Technology, Taiwan, R.O.C. (MOST104-2314-B-384-011-MY3).

\section{REFERENCES}

1. Mackie AR, Losordo DW. CD34-positive stem cells: in the treatment of heart and vascular disease in human beings. Tex Heart Inst J. 2011; 38:474-85.

2. Fadini GP, Losordo D, Dimmeler S. Critical reevaluation of endothelial progenitor cell phenotypes for therapeutic and diagnostic use. Circ Res. 2012; 110:624-37.

3. Asahara T, Masuda H, Takahashi T, Kalka C, Pastore C, Silver M, Kearne M, Magner M, Isner JM. Bone marrow origin of endothelial progenitor cells responsible for postnatal vasculogenesis in physiological and pathological neovascularization. Circ Res. 1999; 85:221-8.

4. Asahara T, Murohara T, Sullivan A, Silver M, van der Zee R, Li T, Witzenbichler B, Schatteman G, Isner JM. Isolation of putative progenitor endothelial cells for angiogenesis. Science. 1997; 275:964-7.

5. Hwang WS, Chen SH, Lin CH, Chang HK, Chen WC, Lin MT. Human umbilical cord blood-derived CD34+ cells can be used as a prophylactic agent for experimental heatstroke. J Pharmacol Sci. 2008; 106:46-55.

6. Chen SH, Chang FM, Chang HK, Chen WC, Huang KF, Lin MT. Human umbilical cord blood-derived CD34+ cells cause attenuation of multiorgan dysfunction during experimental heatstroke. Shock. 2007; 27:663-71.

7. Boltze J, Schmidt UR, Reich DM, Kranz A, Reymann KG, Strassburger M, Lobsien D, Wagner DC, Forschler A, Schabitz WR. Determination of the therapeutic time window for human umbilical cord blood mononuclear cell transplantation following experimental stroke in rats. Cell Transplant. 2012; 21:1199-211.

8. Weise G, Lorenz M, Posel C, Maria Riegelsberger U, Storbeck V, Kamprad M, Kranz A, Wagner DC, Boltze J. Transplantation of cryopreserved human umbilical cord blood mononuclear cells does not induce sustained recovery after experimental stroke in spontaneously hypertensive rats. J Cereb Blood Flow Metab. 2014; 34:e1-9.

9. Chung YC, Ma MC, Huang BY, Chiang HS, Chou SH. Protection of bone marrow-derived CD45+/CD34-/linstromal cells with immunosuppressant activity against ischemia/reperfusion injury in rats. Chin J Physiol. 2011; 54:169-82.

10. Kim SW, Kim H, Yoon YS. Advances in bone marrowderived cell therapy: CD31-expressing cells as next generation cardiovascular cell therapy. Regen Med. 2011; 6:335-49.
11. Alviano F, Fossati V, Marchionni C, Arpinati M, Bonsi L, Franchina M, Lanzoni G, Cantoni S, Cavallini C, Bianchi F, Tazzari PL, Pasquinelli G, Foroni L, et al. Term Amniotic membrane is a high throughput source for multipotent Mesenchymal Stem Cells with the ability to differentiate into endothelial cells in vitro. BMC Dev Biol. 2007; 7:11.

12. Wolbank S, Peterbauer A, Fahrner M, Hennerbichler S, van Griensven M, Stadler G, Redl H, Gabriel C. Dosedependent immunomodulatory effect of human stem cells from amniotic membrane: a comparison with human mesenchymal stem cells from adipose tissue. Tissue Eng. 2007; 13:1173-83.

13. Portmann-Lanz CB, Schoeberlein A, Portmann R, Mohr S, Rollini P, Sager R, Surbek DV. Turning placenta into brain: placental mesenchymal stem cells differentiate into neurons and oligodendrocytes. Am J Obstet Gynecol. 2010; 202:294.e1-.e11.

14. Li Z, Zhao W, Liu W, Zhou Y, Jia J, Yang L. Transplantation of placenta-derived mesenchymal stem cell-induced neural stem cells to treat spinal cord injury. Neural Regen Res. 2014; 9:2197-204.

15. Oliveira MS, Barreto-Filho JB. Placental-derived stem cells: Culture, differentiation and challenges. World J Stem Cells. 2015; 7:769-75.

16. Chen J, Shehadah A, Pal A, Zacharek A, Cui X, Cui Y, Roberts C, Lu M, Zeitlin A, Hariri R, Chopp M. Neuroprotective effect of human placenta-derived cell treatment of stroke in rats. Cell Transplant. 2013; 22:871-9.

17. Ventura C, Cantoni S, Bianchi F, Lionetti V, Cavallini C, Scarlata I, Foroni L, Maioli M, Bonsi L, Alviano F, Fossati V, Bagnara GP, Pasquinelli G, et al. Hyaluronan mixed esters of butyric and retinoic Acid drive cardiac and endothelial fate in term placenta human mesenchymal stem cells and enhance cardiac repair in infarcted rat hearts. J Biol Chem. 2007; 282:14243-52.

18. Kadam S, Muthyala S, Nair P, Bhonde R. Human placentaderived mesenchymal stem cells and islet-like cell clusters generated from these cells as a novel source for stem cell therapy in diabetes. Rev Diabet Stud. 2010; 7:168-82.

19. Bhonde RR, Sheshadri P, Sharma S, Kumar A. Making surrogate beta-cells from mesenchymal stromal cells: perspectives and future endeavors. Int J Biochem Cell Biol. 2014; 46:90-102.

20. Park S, Kim E, Koh SE, Maeng S, Lee WD, Lim J, Shim I, Lee YJ. Dopaminergic differentiation of neural progenitors derived from placental mesenchymal stem cells in the brains of Parkinson's disease model rats and alleviation of asymmetric rotational behavior. Brain Res. 2012; 1466:158-66.

21. Chen SH, Lin MT, Chang CP. Ischemic and oxidative damage to the hypothalamus may be responsible for heat stroke. Curr Neuropharmacol. 2013; 11:129-40.

22. Argaud L, Ferry T, Le QH, Marfisi A, Ciorba D, Achache P, Ducluzeau R, Robert D. Short- and long-term outcomes of 
heatstroke following the 2003 heat wave in Lyon, France. Arch Intern Med. 2007; 167:2177-83.

23. Dematte JE, O’Mara K, Buescher J, Whitney CG, Forsythe $\mathrm{S}$, McNamee T, Adiga RB, Ndukwu IM. Near-fatal heat stroke during the 1995 heat wave in Chicago. Ann Intern Med. 1998; 129:173-81.

24. Liu ZF, Li BL, Tong HS, Tang YQ, Xu QL, Guo JQ, Su L. Pathological changes in the lung and brain of mice during heat stress and cooling treatment. World J Emerg Med. $2011 ; 2: 50-3$.

25. Volkman R, Offen D. Concise Review: Mesenchymal Stem Cells in Neurodegenerative Diseases. Stem Cells. 2017; 35:1867-80.

26. Chen SH, Chang FM, Tsai YC, Huang KF, Lin CL, Lin MT. Infusion of human umbilical cord blood cells protect against cerebral ischemia and damage during heatstroke in the rat. Exp Neurol. 2006; 199:67-76.

27. Heled Y, Fleischmann C, Epstein Y. Cytokines and their role in hyperthermia and heat stroke. J Basic Clin Physiol Pharmacol. 2013; 24:85-96.

28. Boltze J, Reich DM, Hau S, Reymann KG, Strassburger M, Lobsien D, Wagner DC, Kamprad M, Stahl T. Assessment of neuroprotective effects of human umbilical cord blood mononuclear cell subpopulations in vitro and in vivo. Cell Transplant. 2012; 21:723-37.

29. Hsu SF, Chao CM, Chang CP, Lin MT, Cheng BC. Heat shock protein 72 may improve hypotension by increasing cardiac mechanical efficiency and arterial elastance in heatstroke rats. Int J Cardiol. 2016; 219:63-9.

30. Liu K, Lin Y, Xiang L, Yu P, Su L, Mao L. Comparative study of change in extracellular ascorbic acid in different brain ischemia/reperfusion models with in vivo microdialysis combined with on-line electrochemical detection. Neurochem Int. 2008; 52:1247-55.

31. Nilsson OG, Brandt L, Ungerstedt U, Saveland $H$. Bedside detection of brain ischemia using intracerebral microdialysis: subarachnoid hemorrhage and delayed ischemic deterioration. Neurosurgery. 1999; 45:1176-84; discussion 84-5.

32. Eric R, Kandel ER, James H, Schwartz JH, Jessell TM, Siegelbaum SA, Hudspeth AJ (Eds). Principles of Neural Science: McGraw-Hill. 2000.

33. Leon LR, Bouchama A. Heat stroke. Compr Physiol. 2015; 5:611-47.

34. Silvestre JS, Smadja DM, Levy BI. Postischemic revascularization: from cellular and molecular mechanisms to clinical applications. Physiol Rev. 2013; 93:1743-802.

35. Hsuan YC, Lin CH, Chang CP, Lin MT. Mesenchymal stem cell-based treatments for stroke, neural trauma, and heat stroke. Brain Behav. 2016; 6:e00526.

36. Chen SH, Chang FM, Tsai YC, Huang KF, Lin MT. Resuscitation from experimental heatstroke by transplantation of human umbilical cord blood cells. Crit Care Med. 2005; 33:1377-83.

37. Paxinos G, Watson C. The Rat Brain in Stereotaxic Coordinates. Academic Press. 2013; 7th edition: 472.

38. Ungerstedt U. Microdialysis--principles and applications for studies in animals and man. J Intern Med. 1991; 230:365-73.

39. Hillered L, Persson L. Neurochemical monitoring of the acutely injured human brain. Scand J Clin Lab Invest Suppl. 1999; 229:9-18.

40. Hillered L, Persson L, Ponten U, Ungerstedt U. Neurometabolic monitoring of the ischaemic human brain using microdialysis. Acta Neurochir (Wien). 1990; 102:91-7.

41. Esterbauer H, Cheeseman KH. Determination of aldehydic lipid peroxidation products: malonaldehyde and 4-hydroxynonenal. Methods Enzymol. 1990; 186:407-21. 